\title{
Book Review: A Meeting of Masks: Status, Power and Hierarchy in Bangkok by Sophorntavy Vorng
}

\author{
Alexander Franco, Ph.D. \\ Stamford International University, Graduate School of Business \\ alexander.franco@stamford.edu
}

Received Date: July 20, 2017

Accepted Date: July 30, 2017

Published Date: August 04, 2017

This ethnographic work undertakes an ambitious agenda. The author explores Thailand's notions of rank and hierarchy as well as characterizations of a rural-urban divide to explain the political protests and violence that recently occurred in that country.

In casting a broad net of inquiry, the author also set out to examine the dynamics of Bangkok's growing middle class. She found tensions as members of the middle-class struggle for status and upward social mobility amidst urban spaces such as upscale shopping malls by way of conspicuous consumption and outward displays of wealth. Specifically, the author stated two goals of this research: 1) critiquing established representations of a "rupture" (p. 9) between Thailand's rural and urban societies, and;2) demonstrating the socio-economic diversity of Bangkok's middle class, as opposed to its characterization of being uniformly "homogeneous, affluent, educated and upwardly mobile" (p. 9).

This work disappoints on many fronts. The first is regarding its research methodology. The author identified her work as an ethnographic study based "on more than one hundred informants" (p. 17), supposedly representing an array of demographic variables. These informants provided information by way of individual interviews, focus groups and through the author's use of participant observation. However, we are not informed of the actual number of informants or the specifics of their demographic profile. Therefore, the inferential integrity of the sample is in question. The author stated that many informants had "foreign university educations" and "had attended top-tier international schools and universities in Bangkok" (p. 156). However, how many such informants made up her sample to justify a true representation of Bangkok's population or what can be identified as middle class? The omission of such information damages the presentation in what is an academic work whose audience would, therefore, be academic-centric and not layman. But even laymen would question the lack of basic demographic data.

The author claimed to heavily rely on data collected through participatory observation. This research approach is challenging for many reasons, but especially regarding the actual writing of field notes and in not biasing commentary based on the subjectivity infused through actual participation. However, it is not clear whether the author made a proper distinction between direct and participatory observation. In the first, the researcher remains an outsider (whether overt or covert) and merely observes. In the second, the researcher actually takes part in activity. The author cites an incident where she merely observed "middle-class informants" (p. 90) making purchases and another event where she "observed at close quarters...an opulent wedding" (p. 93). The author did not actually participate in the shopping experience (e.g., making purchases or commenting or influencing regarding prices or status symbols, etc.), and did not actually participate in the wedding as, say, a bridesmaid. Both incidents appear to be covert acts of direct participation, not participatory observation. 
One of the author's goals was to dismiss the notion that Bangkok is populated by a homogeneous middle class. However, this seems to have been a straw man and there were no citations to any proponents of this opinion. Unfortunately, what the author failed to do was to present empirical evidence as to the "socioeconomic diversity" (p. 9) of that middle class. The book fails to give us any established numbers which would serve as a background context to an ethnographic exploration. If you wish to explore the dynamics of, for example, a motorcycle gang subculture within a given community, it would be appropriate to state the number of gang members as well as demographic characteristics such as gender, age and ethnicity.

An empirical portrait of the middle class in Bangkok was crucial in the work. How many actual residents fall in that category as opposed to poor or wealthy? Thailand's National Statistical Office records Bangkok's population by quintile breakdown, focusing on percentage of population within specific levels of earned income. However, none of this data was presented in the author's work. The author refers to the Sino-Thai community in Bangkok over two dozen times in the book, usually in reference to their disproportional wealth within the city. However, we are never told how many Sino-Thais reside in Bangkok or what percentage of the city's middle class or overall population they constitute.

Devoid of this crucial data, the reader is, however, subjected to too much information by way of translations of Thai words and phrases. In addition to a translation glossary of 35 Thai words and phrases, the author incorporates approximately 140 such translations throughout the text, thus encumbering the essence of what is being conveyed - and this to a primarily English-speaking audience that would not really be interested in learning a new vocabulary when it is not necessary to understand the substance of the presentation. However, the author does not hesitate to borrow unexplained or badly explained terms such as "neoliberalism urban restructuring" (p. 38), "neoliberal capitalist" (p. 39), and "neoliberal urban spaces" (p. 172). Neoliberalism, a kaleidoscopic bugaboo word anchored in a badly fabricated history, is often used as a beast of burden to pull many untenable propositions. But the real burden was for the author to justify its application by defining its expressed variations in a contextually substantive way. This was not accomplished. Other borrowed jargon led to head scratching phrases such as, "Urbanism is not opposed to ruralism, but rather, incorporates the latter into a hierarchical relationship" (p42).

The other stated goal of the author was to critique simplistic representations of a "rupture" (p. 9) between rural and urban Thai society. The use of the word rupture is unfortunate since it means, or implies, a breach in harmonious relationship. Such a breach never occurred in Thailand. The migration of rural dwellers to Bangkok (and other urban centers) has been ongoing for over two hundred years, following similar ruralto-urban migration patterns around the world. That migration continues to this day despite increased capitalization and infrastructure development in Thailand's rural provinces.

The author attempts to validate the rupture argument by pointing at recent political conflict in Thailand with yellow-shirted protestors supposedly representing the urban middle class and red-shirted protestors presumably representing agricultural workers from the northern rural areas. However, this book was published in 2017 and, therefore, should acknowledge in hindsight that Thailand's recent political conflicts were primarily of an intra-elite nature that superficially appeared to be class based. A power bloc led by the Shinawatras (as respective prime ministers) evolved to eventually challenge, in absolute and monopolistic terms, the traditional ruling coalition of royalist elite families, the military top brass, the Democrat Party, the Bangkok-based, Sino-Thai business community, and the royalist judiciary. To accomplish this, the Shinawatras bought a constituency among farmers in the rural areas and the working class in the urban areas through exuberant vote buying and government handout schemes including the 30-baht universal healthcare program, the one million village investment development fund and a rice subsidy program in which the government promised to purchase rice directly from farmers at above-market prices. When the rice subsidy program collapsed due to corruption and 
incompetence (costing the Thai government some 500 billion Thai baht), the unpaid farmers abandoned the Shinawatras and the red-shirt movement. When farmers threatened to park 100 tractors at the international airport in Bangkok, this was not a protest against the urban middle class. After the rice subsidy fiasco, the Shinawatras had to resort to a violent militia and a small core of ideological radicals, mobilized by Maoist agitators, to continue street protests.

Therefore, the author failed in making a convincing argument that the violence that Thailand experienced was, fundamentally, a manifestation of class conflict and contestation. She cites, as an example, the complete burning down of the Central World Plaza building in Bangkok in 2010 as "a particularly poignant example of the working-class response to their disenfranchisement from Thailand's economic progress" (p.172). However, it is very difficult to burn down a modern building; a forensic investigation of that shopping mall crime scene indicated that the arson was carefully planned and executed. Documented evidence indicated the presence at that crime scene of the Men in Black or black shirts, an elite core from some 300 paid militiamen, armed with AK-47 and M16 assault rifles as well as M79 grenades launchers. These militiamen turned nearby Lumphini Park into a military camp and it is from these Shinawatra hired guns, not Bangkok's normally docile working class, that the well-organized violent destruction originated.

However, the author is correct in stating that there are socio-economic tensions between classes in Bangkok. This follows similar experiences in other parts of the world that also dealt with rural migration to urban areas, within their specific historical context. However, this ethnographic study does not convince the reviewer that the tensions are primarily due to class conflict. The observations in this book, as well as similar material elsewhere, suggest that the source of these are primarily due to a cultural clash.

There is no doubt that Thailand is undergoing cultural changes and structural reorganization. The country is experiencing lower levels of religiosity as Buddhism gives way to a more multi-faith and even secular society. Urbanization absorbs more of the country's population, thus providing greater access to goods that, in turn, allows for more focus on materialism. Commercial marketing celebrates youth over the old and the traditional respect accorded to the elderly. Male domination is being slowly subverted to accommodate gender equality as well as the acceptance of alternative lifestyles.

Yet Thai rurality is still fundamentally Buddhist - more specifically, the hybridization of animism, Brahmanism and Theravada Buddhism. Villages remain Buddhist wat-centric, with social relationships and a radius of trust amongst those constituting the inner-group but with more formal relationships and distrust for outsiders. Buddhism espouses spiritual enlightenment over the accumulation of wealth or socio-economic status. Enjoyment in moderation, harmony and conflict avoidance are also emphasized. As a result, there is a more lax work ethic as well as less emphasis on educational attainment or the acquisition of knowledge for personal development. Mounier (2010, p. 281) observed that in Thailand, "there are no strong traditions of studying, writing, reading and debating. These things, he argues, are felt by Thais to be unnecessary and painful. Tangchuang (2010, p. 217) indicated that the pursuit of educational degrees in Thailand is not for the acquisition of knowledge but for status - a phenomenon the author refers to as "credentialism."

This reviewer suggests that the tensions observed by the author of this book being reviewed occurs when Thais from a Buddhist village upbringing arrive to Bangkok, which is essential a Confucian subculture, made so by an ethnic minority of Sino-Thais whose increasing wealth, over time, allowed them to determine the prevailing culture (certainly the business culture) of the city. Rural Thais, essentially, undergo an assimilation process as they encounter Confucian values being enforced by Sino-Thai business owners. Though many contemporary Sino-Thai businessmen make an attempt to de-emphasize an ethnic-based 
identification (Koning \& Verver, 2013), they continue to operationalize the Confucian Work Ethic (hereafter "CWE"). The CWE stresses the value of and dedication to hard work (as opposed to Thai Buddhist orientation of fun-pleasure and mai pen rai - never mind/don't worry); punctuality (as opposed to Thai flexibility on time); thrift and savings (as opposed to short-term views on money that focus on immediate gratification); and a love of education and the acquisition of wisdom (as opposed to low esteem for wisdom and the earning of diplomas for social status).

These conflicts also occur when rural Thais find themselves with foreign bosses (found throughout almost every sector of the Thai economy), including falang (Caucasians) and Brahman-class Indians, both operationalizing a secularized version of the Protestant Work Ethic which is perceived by many as more severe (or at least more demanding) than the CWE. It is in this cross-cultural work environment that the incident of losing face primarily places itself out, often as a defense mechanism against what are considered to be unreasonable expectations from a work ethic alien to the socialization process experienced in rural Thailand. Failure to effectively assimilate to many of the values of the Confucian sub-culture is most likely due to the fact that the majority of the city's population are not Sino-Thai and confrontation with Confucian or foreign values are primarily limited to episodes in the workplace environment where there is support and solace from like-minded co-workers.

The author cautions that it may be an oversimplification to explain Thai cultural behavior in terms of a Buddhism worldview. However, Thai religiosity, embedded within culture, has a profound impact on how people act, even if they do not necessarily tie particular actions to a theological code or any transcendental consequence. Aspects of Buddhism are infused into tradition and the socialization process which, consequentially, shapes an individual's mind and actions. While the primary value within the Confucian subculture of Bangkok is power, the primary value of Thai Buddhism is harmony, or at least adapting to one's social and cosmological environment, which frequently involves seeking animistic protection from outsiders, often negotiated before a spirit house. The clashing of these two fundamentally different worldviews may very well be the source of much of the tensions the author refers to.

The author indicates that what is highly valued within contemporary Bangkok are, "the Central Thai dialect, pale skin, elite education, a sophisticated urban lifestyle, and material status markers" (p. 170). These characteristics were often tied to the two dozen or so references made about the Sino-Chinese in the book. Within an analytical framework of the rural and working class assimilating into a Confucian subculture, the author's observations can be tied together to show friction that is largely irreconcilable. The financially-related characteristics cited above are virtually unobtainable to rural migrants, the working class and those who have moved upward into a middle-middle class status. A major reason is the inaccessibility to capital. A significant strength of the entrepreneurial sub-culture of Sino-Thais is a powerful bond through a network of family-based interconnections or guanxi (connections). The mutual trust and obligations, commonly strengthened with intermarriages, are often stronger than legalistic arrangements. However, capitalization is mainly kept within the clan membership with the exception of marriages with those of the traditional elite Thai families. In addition to this, Sino-Thais are more apt to marry among themselves, thus following patterns around the world where people have greater social access to their own and, consequently, marry those with a similar socioeconomic level and educational attainment.

Those aspiring to emulate the well-to-do may go to the upscale malls within the Siam-Ratchaprasong hub of Bangkok that the author refers to in her work. However, they lack the money to engage in recurring conspicuous consumption, and most of their purchases are ultimately made at the fast food courts. The three quintiles that make up the strata for middle class status in Bangkok run from about 10,000 baht to 17,000 baht in per capita monthly income. With the Sino-Thai community controlling most of the capital in 
Bangkok, including banks and financial services, and with the very limited possibility of entering the ranks of the wealthy through marriage, financial tensions will continue due to the developing perception of real limitations as to upward mobility beyond the middle-middle class strata.

The author presented over a dozen references in the book regarding skin whitening. She pointed out that those with white skin were accorded greater respect and customer service even if they were casually dressed. Aesthetic preference for white skin also factored into dating as many of her female informants indicated that males in Bangkok were "only attracted to girls with the a muay look, the stereotype of the thin, ghostly pale, and demure Chinese girl" (p. 123). Thai actors and performers are disproportionately Sino-Thai and the marketing and advertising industries, which are Sino-Thai dominated, project the country's standard of what is aesthetic beauty by using Sino-Thais and even Caucasian-Thai models. This feeds into the 66-billion-baht skin whitening industry in Thailand as the non-white population struggles, in vain, to obtain the aesthetic of descendants of an immigrant group whose skin tone is distinct from most of the country's population.

Colorism has been around in Thailand for over two hundred years, at least, and manifested itself as rural Thai entered Bangkok to encounter the then gold-based wealth of white Chinese immigrants and, much later, the entrepreneurial Chinese who fled their mainland after the Chinese civil war. Dark skin came to mean agricultural or manual work, low income, and low educational attainment. Contemporary Thais continue to practice colorism as a matter of identifying others socio-economically and as a point of aesthetic preference for mates or even friends without resorting to actual racism (i.e., outright rejection and even hatred against others for belonging to a particular group). However, to psychologically conform to their place in a skin tone-based, pyramidal hierarchy where they are situated below white skin people, Thais have resorted to placing Indians, Arabs, or those perceived to be as such, below them in their skin-tone hierarchy as an irrational attempt to cope with a self-imposed sense of inferiority. Merely being perceived as looking like an Indian or Arab is sufficient to trigger incivility or outright hostility, certainly poor customer service. If the author were to conduct an ethnographic study of sex workers in Bangkok, using the red-light areas of Soi Cowboy (Asoke) and Nana Entertainment Plaza as polar ends with Sukhumvit Street as a straight line between the two, she will find that at least half of the sex workers in those venues and along that street refuse Indian or Arab men as clients and describe them as dirty or smelly (despite the reputation of male Arab tourists applying too much cologne). Most of these sex workers, often supporting families in rural areas of the country, would rather forego any income on a given night then do business with an Indian or Arab. The hostility is not due to a history of violence since the Thai media (English and native) continually reports that most of the violence against sex workers in Thailand by foreigners are committed by Australians and Europeans.

Unfortunately, what is at play here is also found in places like Brazil and the Dominican Republic where mulattoes (accepting their pyramidal stratum under the minority Caucasians) reject their black compatriots just as mestizos in Latin America look down on and mock the indigenous populations of their respective nations. This ugly manifestation of what can truly be identified as racism in Thailand is, therefore, an unfortunate but not a unique consequence of adhering to aesthetic standards established by outsiders (or others in the minority). Non-Sino-Thais are not likely to generate and maintain white skin with current science. Lighter skin offspring are possible depending on extremely limited opportunities of marriage with Sino-Thais or Caucasian foreigners. Therefore, tensions regarding skin tone will remain until there is a wider sociological recognition of the contemporary dynamics (and consequential tensions) 
of the many attempting to assimilate into the Sino-Thai, Confucian sub-culture of a few.

Ethnographic studies are messy endeavors and challenging because expectations of results usually go beyond mere empirical verification. Comprehensive ethnographies are usually intertwined with sociological, historical and cultural considerations that call for the careful weaving of a rich tapestry. The author is to be commended for her inquiry and certainly this work far exceeds a similar contemporary work, The Way Thais Lead (Persons, 2016), which was heavy in theory but weak in empirical inquiry and verification. Certainly, more research is welcomed regarding the ongoing cultural challenges in the Kingdom of Thailand.

\section{References}

1. Koning, J., \& Verver, M. (2013). Historicizing the 'Ethnic' in Ethnic Entrepreneurship. The Case of the Ethnic Chinese in Bangkok. Entrepreneurship \& Regional Development, 25(5-6), 325-348.

2. Mounier, A. (2010). The teaching and learning process: A theoretical perspective. In A. Mounier \& P. Tanguchuang, (Eds.), Education and Knowledge in Thailand: The Quality Controversy (pp. 269-301). Chiang Mai, Thailand: Silkworm Books.

3. Persons, L. S. (2016). The Way Thais Lead: Face as Social Capital. Chiang Mai, Thailand: Silkworm Press.

4. Tangchuang, P. (2010). Credentialism and the Diploma Disease in Higher Education. In A. Mounier \& P. Tanguchuang, (Eds.), Education and Knowledge in Thailand: The Quality Controversy (pp. 217-237). Chiang Mai, Thailand: Silkworm Books.

Book reviewed:

A Meeting of Masks: Status, Power and Hierarchy in Bangkok

Sophorntavy Vorng

Copenhagen, Denmark: Nordic Institute of Asian Studies Press 2017

Citation: Alexander Franco, Ph.D., Book Review: A Meeting of Masks: Status, Power and Hierarchy in Bangkok by Sophorntavy Vorng". American Research Journal of History and Culture; V3, I1; pp:1-6

Copyright (c) 2017 Alexander Franco, Ph.D. This is an open access article distributed under the Creative Commons Attribution License, which permits unrestricted use, distribution, and reproduction in any medium, provided the original work is properly cited. 